\title{
Small but significant socioeconomic inequalities in axillary staging and treatment of breast cancer in the Netherlands
}

\author{
MJ Aarts ${ }^{*, 1}$, VC Hamelinck ${ }^{2,3}$, E Bastiaannet ${ }^{2,3}$, JWW Coebergh ${ }^{1,4}$, GJ Liefers ${ }^{2}$, AC Voogd ${ }^{1,5}$, M van der Sangen ${ }^{6}$ \\ and WJ Louwman'
}

'Comprehensive Cancer Centre South, Eindhoven Cancer Registry, PO Box 231, 5600 AE, Eindhoven, The Netherlands; ${ }^{2}$ Department of Surgery, Leiden University Medical Center, Leiden, The Netherlands; ${ }^{3}$ Department of Gerontology \& Geriatrics, Leiden University Medical Center, Leiden, The Netherlands; ${ }^{4}$ Department of Public Health, Erasmus Medical Centre Rotterdam, Rotterdam, The Netherlands; ${ }^{5}$ Department of Epidemiology, Research Institute Growth and Development (GROW), Maastricht University, Maastricht, The Netherlands; ${ }^{6}$ Department of Radiation Oncology, Catharina Hospital, Eindhoven, The Netherlands

BACKGROUND: The use of sentinel node biopsy (SNB), lymph node dissection, breast-conserving surgery, radiotherapy, chemotherapy and hormonal treatment for breast cancer was evaluated in relation to socioeconomic status (SES) in the Netherlands, where access to care was assumed to be equal.

METHODS: Female breast cancer patients diagnosed between 1994 and 2008 were selected from the nationwide population-based Netherlands Cancer Registry $(N=176505)$. Socioeconomic status was assessed based on income, employment and education at postal code level. Multivariable models included age, year of diagnosis and stage.

RESULTS: Sentinal node biopsy was less often applied in high-SES patients (multivariable analyses, $\leqslant 49$ years: odds ratio (OR) 0.70 (95\% Cl: 0.56-0.89); 50-75 years: 0.85 (0.73-0.99)). Additionally, lymph node dissection was less common in low-SES patients aged $\geqslant 76$ years (OR $1.34(0.95-1.89))$. Socioeconomic status-related differences in treatment were only significant in the age group 50-75 years. High-SES women with stage TI-2 were more likely to undergo breast-conserving surgery (+ radiotherapy) (OR I.I 5 (I.09-1.22) and OR I.I6 (I.09-1.22), respectively). Chemotherapy use among node-positive patients was higher in the high-SES group, but was not significant in multivariable analysis. Hormonal therapy was not related to SES.

CONCLUSION: Small but significant differences were observed in the use of SNB, lymph node dissection and breast-conserving surgery according to SES in Dutch breast cancer patients despite assumed equal access to health care.

British Journal of Cancer (2012) I 07, I2-17. doi:I0.1038/bjc.2012.205 www.bjcancer.com

Published online 17 May 2012

(C) 2012 Cancer Research UK

Keywords: breast cancer; staging; treatment; socioeconomic factors; population-based; The Netherlands

Breast cancer is the most common cancer in females from Western countries, particularly in Western Europe (Ferlay et al, 2010). Incidence rates are generally highest among women with high socioeconomic status (SES) (Faggiano et al, 1997; Carlsen et al, 2008; National Cancer Intelligence Network, 2009; Spadea et al, 2009). However, at least for the Netherlands, we observed age-specific differences in this association. In women aged 25-44 years, the highest incidence rates were reported for those with high SES, whereas in those aged $\geqslant 65$ years rates were the lowest for those with a high SES. No socioeconomic inequalities were observed in those aged 45-64 years (Aarts et al, 2010).

Survival from breast cancer has been reported to be generally worse in those with low SES (Schrijvers et al, 1995; Bastiaannet et al, 2011), although better survival rates have been observed by others (Faggiano et al, 1997). In the Netherlands, an equal healthcare system is provided and a health insurance is compulsory for all inhabitants. However, survival disparities from breast cancer have been reported. These were partly explained by tumour size

*Correspondence: MJ Aarts; E-mail: research@ikz.nl

Received 16 January 2012; revised 12 April 2012; accepted 18 April 2012; published online 17 May 2012
(Bastiaannet et al, 2011) and by stage differences resulting from differences in attendance to the free population screening programme (Aarts et al, 2011).

Treatment disparities were present in studies from Denmark and the UK, which have shown that deprived women had higher mastectomy rates, although the odds of receiving radiotherapy after breast-conserving surgery was not associated with SES as well as chemotherapy and endocrine treatment (Norredam et al, 1998; Taylor and Cheng, 2003; Henley et al, 2005; Downing et al, 2007; Raine et al, 2010). Furthermore, the use of sentinel node biopsy (SNB) was higher in regions with a high educational level in the US (Halpern et al, 2009), but to our knowledge this has not been studied in other countries.

Although Dutch health care is supposedly equally accessible, socioeconomic treatment disparities were reported for colon, pancreas, prostate and oesophageal cancer (Aarts et al, submitted; Lemmens et al, 2005; van Oost et al, 2006; Bus et al, 2012). However, for breast cancer care it is not known whether there are differences in axillary staging and treatment. Therefore, we investigated the association between SES and the use of SNB, lymph node dissection, breast-conserving surgery, radiotherapy, chemotherapy and hormonal treatment for breast cancer in the Netherlands. 


\section{PATIENTS AND METHODS}

\section{Patient selection}

Female patients with their first primary breast cancer (invasive and in situ) diagnosed between 1994 and 2008 were selected from the Netherlands Cancer Registry. Patients with other tumours before their breast cancer were excluded. The nationwide Dutch network and registry of histopathology and cytopathology regularly submits reports of all diagnosed malignancies to the regional cancer registries. The national hospital discharge databank, which receives discharge diagnoses of admitted patients from all Dutch hospitals, completes case ascertainment. After notification, trained registry personnel collect data on diagnosis, staging and treatment from the medical records, including pathology and surgery reports, about 9 months after diagnosis, using the registration and coding manual of the Dutch Association of Comprehensive Cancer Centres.

Stage was divided according to TNM classification at the year of diagnosis. Pathological T, N and M stage was used; clinical stage was used if pathological was missing.

In the Netherlands, the SNB was gradually implemented from 1998 to 2003; we therefore studied the SNB from 2003 onwards. It is registered in six of nine regional registries; analyses on SNB were limited to these registries and to stage cT1,2N0M0,X.

National guidelines for treatment of breast cancer were introduced in the Netherlands in 2002 (Working Group Treatment Breast Cancer, 2002). Before that time, treatment was based on regional guidelines. Treatment was categorised as breastconserving surgery, external beam radiotherapy after breastconserving surgery, chemotherapy and hormonal therapy. The use of breast-conserving surgery and breast-conserving surgery plus external beam radiotherapy was studied among patients with stage T1,2N0M0,X breast cancer and chemotherapy and hormonal therapy in TanyN $+\mathrm{M} 0$, X breast cancer. The use of chemotherapy was studied from 2002 onwards, as treatment guidelines were rapidly changing before that time. The use strongly increased from 1994 to 2002 and gradually further increased afterwards. We were not able to classify chemotherapy as adjuvant or neoadjuvant.

The population-based screening programme for breast cancer in the Netherlands started around 1990 and covered in
1997 all women aged 50-69 years; in 1998 the upper age limit was extended to 75 .

\section{Socioeconomic status}

Socioeconomic status was assigned to each patient using an areabased measure according to place of residence at the time of diagnosis. The area-based SES was provided by the Netherlands Institute for Social Research and consists of numbers from income, employment and education, which are provided to the institute by a private organisation that collects information by telephone calls with one person per 6-digit postal code area; this person is seen as representative for his or her area. Next, numbers are aggregated to 4-digit postal code areas. Validation studies indicate that these numbers at aggregated level approach the true situation (Tesser et al, 1995). A higher score represents a high social deprivation (low SES) and a low score represents little social deprivation and consequently a high SES. Scores were divided into quintiles.

\section{Statistical analysis}

All statistical tests were two-sided and were considered significant if $P \leqslant 0.05$. The distribution of sociodemographic and clinical characteristics was studied across the SES strata. Significance was tested with non-parametric tests (continuous variables) and $\chi^{2}$-tests (categorical variables).

Analyses were stratified according to the age groups $\leqslant 49$, $50-75, \geqslant 76$. The odds ratios (OR) were stratified by these age categories and adjusted for age (continuously), year of diagnosis, SES and T-stage. After excluding patients with unknown SES $(N=445)$ and non-carcinomas $(N=1548)$, data on 176505 patients were analysed.

\section{RESULTS}

Patients with highest SES were on average 3 years younger $(P<0.0001)$ and had a lower stage of disease than patients with the lowest SES $(P<0.001$; Table 1$)$.

The use of the SNB procedure for stage cT1,2N0M0,X breast cancer increased from $74 \%$ in 2003 to $88 \%$ in 2008 . In general,

\begin{tabular}{|c|c|c|c|c|c|c|c|c|c|c|}
\hline & \multicolumn{10}{|c|}{ Socioeconomic status } \\
\hline & $\mathbf{N}$ & $\%$ & $\mathbf{N}$ & $\%$ & $N$ & $\%$ & $N$ & $\%$ & $\mathbf{N}$ & $\%$ \\
\hline \multicolumn{11}{|c|}{ Period of diagnosis } \\
\hline $1994-1998$ & 10234 & 23 & 10296 & 18 & 10413 & 20 & 9372 & 20 & || 689 & 20 \\
\hline 1999-2003 & 11990 & 20 & 11616 & 21 & 11580 & 19 & 12695 & 19 & | 845 & 20 \\
\hline \multicolumn{11}{|c|}{ Age at diagnosis**\# } \\
\hline Mean & 62.2 & & 61.4 & & 60.7 & & 59.9 & & 59.3 & \\
\hline $0-49$ & 7673 & 22 & 8003 & 23 & 8477 & 24 & 9128 & 26 & 10101 & 29 \\
\hline $50-75$ & 20823 & 59 & 21314 & 60 & 21339 & 60 & 21104 & 60 & 20058 & 57 \\
\hline $76+$ & 6805 & 19 & 5984 & 17 & 5485 & 16 & 5069 & 14 & 5142 & 15 \\
\hline \multicolumn{11}{|l|}{ TNM stage* } \\
\hline Unknown & 396 & । & 388 & । & 380 & । & 335 & I & 455 & । \\
\hline
\end{tabular}

Abbreviation: TNM $=$ tumour-node-metastasis. ${ }^{*} P<0.0001$ ( $\chi^{2}$-test). ${ }^{\#} P<0.0001$ ( $t$-test). 
Table 2 The use of the sentinel node procedure and additional lymph node dissection for breast cancer patients in the Netherlands, diagnosed 2003-2008, stage cTI,2N0M0,X

\begin{tabular}{|c|c|c|c|c|c|c|c|c|c|c|c|c|c|c|}
\hline \multirow{2}{*}{$\begin{array}{l}\text { Age (years) } \\
\leqslant 49\end{array}$} & \multirow{2}{*}{$\begin{array}{l}\text { Socioeconomic status } \\
\text { I. Highest }\end{array}$} & \multirow{2}{*}{$\frac{N_{\text {total }}}{1262}$} & \multicolumn{6}{|c|}{ Sentinel node biopsy } & \multicolumn{6}{|c|}{$\begin{array}{l}\text { Lymph node dissection in patients with } \\
\text { sentinel node biopsy }\end{array}$} \\
\hline & & & $\frac{\% \text { SNB }}{84.0}$ & $\frac{P \text {-value }}{0.1}$ & $\begin{array}{l}\mathbf{O R} \\
0.70\end{array}$ & \multicolumn{2}{|c|}{$95 \% \mathrm{Cl}$} & $\begin{array}{c}\text { Trend } \\
0.053\end{array}$ & $\frac{\text { \% LND }}{36.4}$ & $\begin{array}{c}P \text {-value } \\
0.7\end{array}$ & $\begin{array}{l}\text { OR } \\
0.90\end{array}$ & \multicolumn{2}{|c|}{$95 \% \mathrm{Cl}$} & $\frac{\text { Trend }}{0.7}$ \\
\hline & 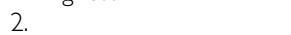 & 1305 & 85.4 & & 0.80 & 0.63 & 1.02 & & 36.6 & & 0.91 & 0.76 & 1.08 & \\
\hline & 3. Intermediate & $|40|$ & 85.9 & & 0.84 & 0.66 & 1.06 & & 36.4 & & 0.90 & 0.75 & 1.07 & \\
\hline & 4. & $|43|$ & 86.2 & & 0.87 & 0.69 & 1.11 & & 37.1 & & 0.91 & 0.76 & 1.08 & \\
\hline & 2. & 3405 & 87.6 & & 0.90 & 0.77 & 1.04 & & 30.3 & & 1.03 & 0.93 & 1.16 & \\
\hline & 3. Intermediate & 3832 & 88.9 & & 0.97 & 0.84 & 1.12 & & 29.6 & & 1.03 & 0.93 & 1.15 & \\
\hline & 4. & 4209 & 88.3 & & 0.96 & 0.84 & 1.11 & & 29.0 & & 0.99 & 0.89 & 1.10 & \\
\hline & 5. Lowest & 3613 & 88.5 & & 1.00 & & & & 29.2 & & 1.00 & & & \\
\hline$\geqslant 76$ & 1. Highest & 506 & 53.2 & 0.1 & 1.01 & 0.80 & 1.28 & 0.06 & 27.1 & 0.01 & 1.34 & 0.95 & 1.89 & 0.01 \\
\hline & & 668 & 46.1 & & 0.79 & 0.64 & 0.98 & & 30.2 & & 1.55 & 1.11 & 2.14 & \\
\hline & 3. Intermediate & 793 & 52.7 & & 1.10 & 0.90 & 1.36 & & 31.1 & & 1.64 & 1.21 & 2.21 & \\
\hline
\end{tabular}

Abbreviations: 95\% Cl=95\% confidence interval; $L N D=$ lymph node dissection; $O R=$ odds ratio, adjusted for age, year of diagnosis, T-stage and histology; SNB = sentinel node biopsy. $P$-values are from $\chi^{2}$ test. Trend refers to $P$-value from trend test.

Table 3 Use of therapies for breast cancer in the Netherlands according to socioeconomic status, diagnosed during 1994-2008

\begin{tabular}{|c|c|c|c|c|c|c|c|c|c|c|c|c|c|c|c|c|c|c|}
\hline & \multicolumn{18}{|c|}{ Age at diagnosis } \\
\hline \multicolumn{19}{|c|}{ Breast-conserving surgery, $T 1,2 \mathrm{NOMO}, \mathrm{X}^{\mathrm{a}}$} \\
\hline I. Highest SES & 60.9 & 0.8 & 0.95 & 0.86 & 1.04 & 0.7 & 64.1 & $<0.0001$ & 1.15 & 1.09 & 1.22 & $<0.0001$ & 24.0 & 0.02 & 1.21 & 1.06 & 1.38 & 0.02 \\
\hline 2. & 61.2 & & 0.97 & 0.88 & 1.07 & & 63.8 & & 1.09 & 1.03 & 1.16 & & 22.6 & & 1.10 & 0.96 & 1.26 & \\
\hline 5. Lowest SES & 61.5 & & 1.00 & & & & 60.4 & & 1.00 & & & & 20.6 & & 1.00 & & & \\
\hline \multicolumn{19}{|c|}{ Breast-conserving surgery + radiotherapy, $T I, 2 N O M O, X^{a}$} \\
\hline I. Highest SES & 58.9 & 0.8 & 0.96 & 0.87 & 1.05 & 0.8 & 62.3 & $<0.0001$ & 1.16 & 1.09 & 1.22 & $<0.0001$ & 18.3 & 0.5 & 1.10 & 0.95 & 1.28 & 0.5 \\
\hline 2. & 59.6 & & 0.99 & 0.90 & 1.09 & & 61.9 & & 1.10 & 1.04 & 1.16 & & 17.8 & & 1.05 & 0.90 & 1.22 & \\
\hline 3. Intermediate & 59.1 & & 0.97 & 0.88 & 1.07 & & 60.5 & & 1.05 & 0.99 & I.11 & & 16.6 & & 0.96 & 0.83 & 1.11 & \\
\hline 4. & 58.3 & & 0.95 & 0.86 & 1.05 & & 60.0 & & 1.04 & 0.99 & 1.10 & & 17.1 & & 1.02 & 0.88 & 1.17 & \\
\hline \multicolumn{19}{|c|}{ Hormonal therapy, Tany $N+M 0, X^{b}$} \\
\hline 2. & 50.4 & & 1.11 & 1.00 & 1.23 & & 71.3 & & 1.01 & 0.93 & 1.09 & & 78.9 & & 0.93 & 0.79 & 1.10 & \\
\hline 3. Intermediate & 48.4 & & 1.01 & 0.91 & 1.12 & & 71.7 & & 1.00 & 0.93 & 1.08 & & 81.0 & & 1.04 & 0.88 & 1.22 & \\
\hline 4. & 48.4 & & 1.02 & 0.91 & 1.13 & & 71.5 & & 0.98 & 0.90 & 1.06 & & 77.9 & & 0.87 & 0.74 & 1.01 & \\
\hline 5. Lowest SES & 49.3 & & 1.00 & & & & 72.1 & & 1.00 & & & & 80.3 & & 1.00 & & & \\
\hline \multicolumn{19}{|c|}{ Chemotherapy, TanyN $+M O, X^{c}$} \\
\hline I. Highest SES & 93.2 & 0.3 & 0.95 & 0.73 & 1.24 & 0.3 & 61.7 & $<0.0001$ & 1.11 & 0.98 & 1.26 & 0.5 & 2.4 & 0.2 & 1.08 & 0.56 & 2.09 & 0.1 \\
\hline 2. & 93.3 & & 0.97 & 0.75 & 1.27 & & 58.8 & & 1.03 & 0.91 & 1.17 & & 1.3 & & 0.45 & 0.22 & 0.91 & \\
\hline 3. Intermediate & 94.1 & & 1.10 & 0.83 & 1.45 & & 57.2 & & 1.01 & 0.89 & 1.14 & & 1.9 & & 0.62 & 0.32 & 1.19 & \\
\hline 4. & 92.4 & & 0.83 & 0.63 & 1.08 & & 56.1 & & 1.02 & 0.90 & 1.15 & & 1.8 & & 0.67 & 0.36 & 1.25 & \\
\hline 5. Lowest SES & 93.8 & & 1.00 & & & & 55.3 & & 1.00 & & & & 2.9 & & 1.00 & & & \\
\hline
\end{tabular}

Abbreviations: $95 \% \mathrm{Cl}=95 \%$ confidence interval; $O R=$ odds ratio; $S E S=$ socioeconomic status. $P$-value refers to $\chi^{2}$-test. Trend refers to $P$-value for trend. ${ }^{\mathrm{a}} \mathrm{OR}$ adjusted for age (continuously), year of diagnosis, T-stage (T2N0 vs TIN0). ${ }^{b} \mathrm{OR}$ adjusted for age (continuously), year of diagnosis, T-stage (T2N+, T3N+, T4N+ vs TIN +). ${ }^{\mathrm{C}}$ rom 2002 onwards. OR adjusted for age (continuously), year of diagnosis, T-stage (TIN+, T3N+, T4N + vs T2N+).

high-SES patients less often received SNB, with 1-3\% lower rates in high- $v$ s low-SES patients aged $\leqslant 75$, but not statistically significant (Table 2). These differences were significant in multivariable analyses (age $\leqslant 49$ : OR 0.70 (95\% CI: $0.56-0.89$ ); $50-75$ years: 0.85 $(0.73-0.99))$. In the oldest age group no consistent pattern on the use of SNB appeared. Compared with high SES, rates of lymph node dissection in addition to SNB were slightly higher in low-SES patients in the youngest age group (36\% vs $39 \%$, not statistically significant), and lower in low-SES patients in the oldest group ( $27 \%$ in high SES $v s 22 \%$ in low SES, $P=0.01$ ). In multivariable 
analyses, among the patients aged $\geqslant 76$ receiving SNB, those with high SES more often received lymph node dissection compared with those with low SES, although not statistically significant for the highest SES group (OR 1.34 (95\% CI: 0.95-1.89)).

Small, statistically significant socioeconomic differences were present in treatment selection in those aged 50-75 years. The use of breast-conserving surgery was slightly higher in high-SES patients (stage T1,2N0M0,X), i.e. $64 \%$ of patients with high SES compared with $60 \%$ of those with low SES $\left(\chi^{2}\right.$-test $P<0.0001$; Table 3). Nearly all of these patients received additional radiotherapy (97\%), which was not significantly different between the SES groups. In multivariable analyses, the odds of breastconserving surgery remained significantly increased (OR 1.15 (95\% CI: 1.09-1.22) for high $v s$ low SES), also for breast-conserving surgery plus radiotherapy (OR 1.16 (95\% CI: 1.09-1.22); Table 3). In this early stage, an inverse association was observed for mastectomy, with lower rates in high-SES women aged $50-75$ years (data not shown).

In those aged 50-75 years, the use of endocrine treatment was not related to SES, neither in univariable nor in multivariable analyses (Table 3). Rates of chemotherapy for node-positive breast cancer were highest in high-SES patients (62\% vs 55\% in low SES, $\chi^{2}$-test $\left.P<0.0001\right)$, but were no longer significant in multivariable analyses (Table 3).

Of all therapies mentioned above, none was significantly related to SES in women aged $<50$ years. In women of age $\geqslant 76$ years, the only significant associations were observed for breast-conserving surgery, with higher rates in the high-SES group $\left(\chi^{2}\right.$-test $P=0.02$, OR high $v s$ low SES 1.21 (95\% CI: 1.06-1.38)), and for chemotherapy, in which rates were reduced in the second highest SES group (OR 0.45 (95\% CI: 0.22-0.91). The use of breastconserving surgery and radiotherapy combined, however, was not significantly related to SES (OR 1.10 (95\% CI: 0.95-1.28)).

\section{DISCUSSION}

This study shows that in the Netherlands, a country with assumed equal access to care, breast cancer patients with high SES were less likely to undergo SNB and, in the oldest group, more likely to receive additionally lymph node dissection. Furthermore, in patients aged 50-75 years the use of breast-conserving surgery and chemotherapy was significantly related to SES, although the absolute differences between the SES groups were generally small. In early-stage breast cancer, the use of breast-conserving surgery (+ radiotherapy) was the highest in patients with high SES. This could not be fully explained by patient age, year of diagnosis and T-stage. Among the patients with node-positive breast cancer, a higher use of chemotherapy was observed among those with high SES. This difference, however, disappeared after adjustment for stage, age and year of diagnosis.

A prior US study showed higher rates of lymph node biopsy/ sampling, that is, either axillary lymph node dissection or SNB, in areas where the education level was higher, although the absolute differences were small (Halpern et al, 2009). Our data suggest a poorer staging of the axillary lymph nodes and abandoning surgery in the armpit in patients with high SES. We cannot explain this observation as we expected the rates to increase with higher SES owing to - among others - better understanding of the importance of axillary staging. Possibly, patients with high SES are more conscious of the side effects of lymph node dissection, such as lymph oedema, and therefore are more inclined not to undergo this therapy. Previously, older age was associated with reduced likelihood of receiving lymph node biopsy (Halpern et al, 2009), but the mean age differed by only 3 years in our study, suggesting that age only little affected the staging procedure. Another study stated that among women undergoing breast-conserving surgery, those with comorbid conditions were less likely to receive axillary dissection (Louwman et al, 2005). As cancer patients with high SES have fewer comorbidities (Louwman et al, 2010), higher rates of axillary dissection would be expected among high-SES patients. We had no information on comorbidities in this study, but it probably has not contributed to the lower rates of SNB in high-SES patients in our study population. Besides, in the US, patients treated in hospitals with higher patient volumes were more likely to receive lymph node biopsy (Halpern et al, 2009). Possibly this has affected our results as well. Also, in the Netherlands, staging procedures and type of surgery depended on hospital characteristics, such as volume, with reducing differences over time (van Steenbergen et al, 2010). It should be noted, however, that absolute differences in our study were small and that statistical significance may have resulted from the large number of patients.

Our results on treatment selection are in line with and the order of magnitude is fairly similar to studies from Denmark and the UK. These studies have shown that women with a lower SES had higher mastectomy rates (Norredam et al, 1998; Taylor and Cheng, 2003; Henley et al, 2005) and lower breast-conserving surgery rates (Taylor and Cheng, 2003; Downing et al, 2007; Raine et al, 2010), although an age-dependent association has been observed as well (Thomson et al, 2001). Adjustment for stage explained the higher mastectomy rates observed in low SES (Henley et al, 2005), whereas the association remained significant after stratification by tumour size (Taylor and Cheng, 2003) and stage (our study, early stage (data not shown)). This implies that type of surgery chosen for the SES groups is not fully explained by stage and age in earlystage disease. Because of higher prevalence of concomitant diseases in patients with low SES (Louwman et al, 2010), type of surgery is expected to be less invasive owing to the poor general condition in low SES patients. In fact, we observed higher invasive surgery (mastectomy) rates in low SES. Presence of comorbidities might also be indicative of mastectomy to avoid the effects of radiotherapy, but this has not been studied before. A Northern Italian study found that presence of comorbidities reduced the odds of receiving radiotherapy after breast-conserving surgery (Rosato et al, 2009). Besides, that study also reported no educational differences in treatment of early-stage breast cancer after adjustment for comorbidities and hospital characteristics (Rosato et al, 2009). As discussed previously, hospital characteristics were affecting treatment selection, including type of surgery and use of radiotherapy, in the Netherlands as well (Vulto et al, 2005; Siesling et al, 2007; van Steenbergen et al, 2010), but we could not take these into account in our analyses. Nor were we able to investigate the contributions of ER status or grade, but previously these factors were reported to be not associated to SES (Henley et al, 2005). More active involvement of the patient in decision making led to higher mastectomy rates (Katz et al, 2005), but the effects in the Netherlands remain to be studied.

In our study, in accordance with the Dutch treatment guidelines (Oncoline. www.oncoline.nl.), nearly all patients undergoing breast-conserving surgery received additional radiotherapy $(97 \%)$ and no differences were observed between the SES groups. Our results are in line with a study from the UK, in which the odds of receiving adjuvant radiotherapy was not associated with deprivation (Downing et al, 2007). Compared with the US, our rates of adjuvant radiotherapy are high (97\% vs $73 \%$ ) (Smith et al, 2010). Furthermore, in the US, large SES differences were observed, with adjuvant radiotherapy rates of $67 \%$ in patients with low SES vs $78 \%$ in those with high SES in the period 1991-2002, which were not explained by stage, hormone receptor status, grade, chemotherapy, comorbidity and surgeon characteristics (Hershman et al, 2008). Similar differences were observed in another US study investigating adjuvant radiotherapy rates according to race, which reported $74 \%$ in whites vs $65 \%$ in blacks (Smith et al, 2010), which remained also significant after adjustment for demographic, clinical (including comorbidities) and socioeconomic covariates. 
Previous studies have reported inconsistent results with respect to the associations between SES and adjuvant radiotherapy, chemotherapy and endocrine treatment (Macleod et al, 2000; Taylor and Cheng, 2003; Downing et al, 2007), with higher rates in high SES in some studies but no association in others (Macleod et al, 2000; Downing et al, 2007; Bhargava and $\mathrm{Du}, 2009$ ). Low educational level was associated with reduced doses of chemotherapy, whereas presence of comorbidities was not associated (Griggs et al, 2007). No data were available on chemotherapy doses from the Netherlands Cancer Registry. Besides, we have used the pathological staging supplemented with clinical TNM in case postoperative data were missing. As we were not able to classify chemotherapy as adjuvant or neoadjuvant, the staging may not be completely correct for the patients who received neoadjuvant chemotherapy.

Higher education predicted hormonal therapy use in older US breast cancer survivors (Yen et al, 2011). For those on hormonal therapy, wealthier women and women with insurance coverage for some or all medication costs were more likely to receive an aromatase inhibitor, which is prescribed by the American Society for Clinical Oncology (ASCO) (Yen et al, 2011). Owing to the Dutch obligatory health insurance for every inhabitant, insurance status is unlikely to affect treatment selection. This is in line with our finding that hormonal therapy was not related to SES in our study.

Unfortunately, patient preferences in itself could not be taken into account in this study. For example, the choice of mastectomy depends on the interplay between the surgeon's recommendations and patients' preferences for treatment (Hawley, 2010). The role of patient decision making (Smith et al, 2009) is likely to be influenced by health literacy, that is, 'The degree to which individuals have the capacity to obtain, process, and understand basic health information and services needed to make appropriate health decisions' (National Network of Libraries of Medicine, 2010). Low health literacy may lead to treatment options that are not fully understood, and therefore some patients may not receive the most appropriate treatment for their medical condition (Merriman et al, 2002). As SES can be linked with education, those with low SES are expected to be more vulnerable to low health literacy. A solution towards solving this might be to focus more on clear and adapted communication by health-care providers. In contrast, some patients do not want to be very involved in decision making (Lantz et al, 2005; Levinson et al, 2005).

Our study findings might be influenced by several limitations. First, we had no information on the presence of comorbidities, which may have affected therapy selection. Second, data on grade,

\section{REFERENCES}

Aarts MJ, van der Aa MA, Coebergh JW, Louwman WJ (2010) Reduction of socioeconomic inequality in cancer incidence in the South of the Netherlands during 1996-2008. Eur J Cancer 46: 2633-2646

Aarts MJ, Voogd AC, Duijm LEM, Coebergh JW, Louwman M (2011) Socioeconomic inequalities in attending the mass screening for breast cancer in the south of the Netherlands - associations with stage at diagnosis and survival. Breast Cancer Res Treat 128: 517-525

Bastiaannet E, de Craen AJ, Kuppen PJ, Aarts MJ, van der Geest LG, van de Velde CJ, Westendorp RG, Liefers GJ (2011) Socioeconomic differences in survival among breast cancer patients in the Netherlands not explained by tumor size. Breast Cancer Res Treat 127: 721-727

Berkman LF, Macintyre S (1997) The measurement of social class in health studies: old measures and new formulations. IARC Sci Publ 51-64

Bhargava A, Du XL (2009) Racial and socioeconomic disparities in adjuvant chemotherapy for older women with lymph node-positive, operable breast cancer. Cancer 115: 2999-3008

Bos V, Kunst AE, Mackenbach J (2000) Nationale gegevens over sociaaleconomische sterfteverschillen op basis van informatie over kleine geografische eenheden [in Dutch]. In Verslag aan de
ER status and PR status were not available, which might have affected our results. Third, we had no information on hospital characteristics, which affected therapy selection in Italy and the Netherlands; however, in the latter study, regional and hospital variation reduced over time (Rosato et al, 2009; van Steenbergen et al, 2010). Fourth, in this study we have used a measure of SES based on 6-digit postal code of the residential area. Our results may therefore be subject to ecological fallacy. Furthermore, our findings may be explained by some residual confounding. Although this measure of SES is not based on individual data on income, education or occupation, it covers a relatively small geographical area and thus is likely to represent a reliable approximation of individual SES. Previous studies in the Netherlands have proven that socioeconomic differences based on neighbourhood data tend to reflect socioeconomic differences accurately at the individual level (Bos et al, 2000, 2001; Smits et al, 2001). Furthermore, as the measure of SES used in this study is based on several outcomes, it also applies to older women (born before 1955), although their occupation or education does not always properly reflect their social class (Berkman and Macintyre, 1997).

Nevertheless, we have used population-based nationwide data, including all breast cancer patients from the Netherlands. We have thus provided a complete overview of the association between SES and the staging and treatment selection of breast cancer, which has not been done before.

\section{CONCLUSION}

Small but significant differences were observed in the use of SNB, lymph node dissection and breast-conserving surgery according to SES in Dutch breast cancer patients despite the assumed equal access to health care.

\section{ACKNOWLEDGEMENTS}

We would like to thank Rudi Roumen, surgeon at Máxima Medical Centre Eindhoven, for his useful comments on the manuscript. We also acknowledge the Netherlands Cancer Registry. Victoria Hamelinck, Esther Bastiaannet and Gerrit-Jan Liefers would like to thank the Dutch Cancer Society (KWF 2007-3968).

\section{Conflict of interest}

The authors declare no conflict of interest.
Programmacommissie Sociaal-economische gezondheidsverschillen II. Instituut Maatschappelijke Gezondheidszorg, Erasmus Universiteit: Rotterdam

Bos V, Kunst AE, Mackenbach JP (2001) De omvang van sociaaleconomische verschillen gemeten op buurtniveau: vergelijking met schattingen op basis van informatie op individueel niveau [in Dutch]. In Sociaal-economische gezondheidsverschillen: Van verklaren naar verkleinen, Stronks K (ed) Vol. 5, pp 8-20. Zon/MW: Den Haag

Bus P, Aarts MJ, Lemmens VE, Van Oijen MG, Creemers GJ, Nieuwenhuijzen GA, Van Baal JW, Siersema PD (2012) The effect of socioeconomic status on staging and treatment decisions in esophageal cancer. J Clin Gastroenterol; e-pub ahead of print 28 March 2012; doi:10.1097/MCG.0b013e31824e8ff8

Carlsen K, Hoybye MT, Dalton SO, Tjonneland A (2008) Social inequality and incidence of and survival from breast cancer in a population-based study in Denmark, 1994-2003. Eur I Cancer 44: 1996-2002

Downing A, Prakash K, Gilthorpe MS, Mikeljevic JS, Forman D (2007) Socioeconomic background in relation to stage at diagnosis, treatment and survival in women with breast cancer. $B r$ J Cancer 96: 836-840 
Faggiano F, Partanen T, Kogevinas M, Boffetta P (1997) Socioeconomic differences in cancer incidence and mortality. IARC Sci Publ 65-176

Ferlay J, Shin HR, Bray F, Forman D, Mathers C, Parkin DM (2010) GLOBOCAN 2008, Cancer Incidence and Mortality Worldwide: IARC Cancer Base No. 10 [Internet]. International Agency for Research on Cancer: Lyon, Available from: http://globocan.iarc.fr (accessed 15 February 2011)

Griggs JJ, Culakova E, Sorbero ME, van Ryn M, Poniewierski MS, Wolff DA, Crawford J, Dale DC, Lyman GH (2007) Effect of patient socioeconomic status and body mass index on the quality of breast cancer adjuvant chemotherapy. J Clin Oncol 25: 277-284

Halpern MT, Chen AY, Marlow NS, Ward E (2009) Disparities in receipt of lymph node biopsy among early-stage female breast cancer patients. Ann Surg Oncol 16: 562-570

Hawley ST (2010) Involving patients in the decision-making process regarding breast cancer treatment: implications for surgery utilization. Womens Health (Lond Engl) 6: 161-164

Henley NC, Hole DJ, Kesson E, Burns HJ, George WD, Cooke TG (2005) Does deprivation affect breast cancer management? $\mathrm{Br} J$ Cancer 92: 631-633

Hershman DL, Buono D, McBride RB, Tsai WY, Joseph KA, Grann VR, Jacobson JS (2008) Surgeon characteristics and receipt of adjuvant radiotherapy in women with breast cancer. I Natl Cancer Inst 100: 199-206

Katz SJ, Lantz PM, Janz NK, Fagerlin A, Schwartz K, Liu L, Deapen D, Salem B, Lakhani I, Morrow M (2005) Patient involvement in surgery treatment decisions for breast cancer. J Clin Oncol 23: 5526-5533

Lantz PM, Janz NK, Fagerlin A, Schwartz K, Liu L, Lakhani I, Salem B, Katz SJ (2005) Satisfaction with surgery outcomes and the decision process in a population-based sample of women with breast cancer. Health Serv Res 40: 745-767

Lemmens VE, van Halteren AH, Janssen-Heijnen ML, Vreugdenhil G, Repelaer van Driel OJ, Coebergh JW (2005) Adjuvant treatment for elderly patients with stage III colon cancer in the southern Netherlands is affected by socioeconomic status, gender, and comorbidity. Ann Oncol 16: 767-772

Levinson W, Kao A, Kuby A, Thisted RA (2005) Not all patients want to participate in decision making. A national study of public preferences. J Gen Intern Med 20: 531-535

Louwman WJ, Aarts MJ, Houterman S, van Lenthe FJ, Coebergh JW, Janssen-Heijnen ML (2010) A 50\% higher prevalence of life-shortening chronic conditions among cancer patients with low socioeconomic status. Br J Cancer 103: 1742-1748

Louwman WJ, Janssen-Heijnen ML, Houterman S, Voogd AC, van der Sangen MJ, Nieuwenhuijzen GA, Coebergh JW (2005) Less extensive treatment and inferior prognosis for breast cancer patient with comorbidity: a population-based study. Eur J Cancer 41: 779-785

Macleod U, Ross S, Twelves C, George WD, Gillis C, Watt GC (2000) Primary and secondary care management of women with early breast cancer from affluent and deprived areas: retrospective review of hospital and general practice records. BMJ 320: 1442-1445

Merriman B, Ades T, Seffrin JR (2002) Health literacy in the information age: communicating cancer information to patients and families. $C A$ Cancer J Clin 52: 130-133

National Cancer Intelligence Network (2009) Cancer Incidence by Deprivation. England, 1995-2004, London

National Network of Libraries of Medicine (2010) In Health Literacy, Glasman P (ed) Vol. 2010, Bethesda
Norredam M, Groenvold M, Petersen JH, Krasnik A (1998) Effect of social class on tumour size at diagnosis and surgical treatment in Danish women with breast cancer. Soc Sci Med 47: 1659-1663

Raine R, Wong W, Scholes S, Ashton C, Obichere A, Ambler G (2010) Social variations in access to hospital care for patients with colorectal, breast, and lung cancer between 1999 and 2006: retrospective analysis of hospital episode statistics. BMJ 340: b5479

Rosato R, Sacerdote C, Pagano E, Di Cuonzo D, Baldi I, Bordon R, Ponti A, Bertetto O, Segnan N, Merletti F, Vineis P, Ciccone G (2009) Appropriateness of early breast cancer management in relation to patient and hospital characteristics: a population based study in Northern Italy. Breast Cancer Res Treat 117: 349-356

Schrijvers CT, Mackenbach JP, Lutz JM, Quinn MJ, Coleman MP (1995) Deprivation and survival from breast cancer. Br J Cancer 72: 738-743

Siesling S, van de Poll-Franse LV, Jobsen JJ, Repelaer van Driel OJ, Voogd AC (2007) Explanatory factors for variation in the use of breast conserving surgery and radiotherapy in the Netherlands, 1990-2001. Breast 16: 606-614

Smith DP, King MT, Egger S, Berry MP, Stricker PD, Cozzi P, Ward J, O'Connell DL, Armstrong BK (2009) Quality of life three years after diagnosis of localised prostate cancer: population based cohort study. BMJ 339: b4817

Smith GL, Shih YC, Xu Y, Giordano SH, Smith BD, Perkins GH, Tereffe W, Woodward WA, Buchholz TA (2010) Racial disparities in the use of radiotherapy after breast-conserving surgery: a national Medicare study. Cancer 116: 734-741

Smits J, Keij I, Westert GP (2001) Effecten van sociaal-economische status van kleine, middelgrote en grote geografische eenheden op de sterfte [in Dutch]. Maandstatistiek van de bevolking 11: 4-10

Spadea T, D’Errico A, Demaria M, Faggiano F, Pasian S, Zanetti R, Rosso S, Vicari P, Costa G (2009) Educational inequalities in cancer incidence in Turin, Italy. Eur J Cancer Prev 18: 169-178

Taylor A, Cheng KK (2003) Social deprivation and breast cancer. J Public Health Med 25: 228-233

Tesser P, Van Praag C, Van Dugteren F, Herweijer L, Van der Wouden H (1995) Rapportage minderheden 1995. Sociaal en Cultureel Planbureau. In VUGA (ed) Rijswijk: Den Haag

Thomson CS, Hole DJ, Twelves CJ, Brewster DH, Black RJ (2001) Prognostic factors in women with breast cancer: distribution by socioeconomic status and effect on differences in survival. J Epidemiol Community Health 55: 308-315

van Oost FJ, Luiten EJ, van de Poll-Franse LV, Coebergh JW, van den Eijnden-van Raaij AJ (2006) Outcome of surgical treatment of pancreatic, peri-ampullary and ampullary cancer diagnosed in the south of The Netherlands: a cancer registry based study. Eur J Surg Oncol 32: 548-552 van Steenbergen LN, van de Poll-Franse LV, Wouters MW, JansenLandheer ML, Coebergh JW, Struikmans H, Tjan-Heijnen VC, van de Velde CJ (2010) Variation in management of early breast cancer in the Netherlands, 2003-2006. Eur J Surg Oncol 36(Suppl 1): S36-S43

Vulto JC, Louwman WJ, Poortmans PM, Coebergh JW (2005) Hospital variation in referral for primary radiotherapy in South Netherlands, 1988-1999. Eur J Cancer 41: 2722-2727

Working Group Treatment Breast Cancer (2002) Guideline Treatment Breast Cancer [Richtlijn behandeling mammacarcinoom]. Van Zuiden Communications: The Netherlands, (in Dutch)

Yen TW, Czypinski LK, Sparapani RA, Guo C, Laud PW, Pezzin LE, Nattinger AB (2011) Socioeconomic factors associated with adjuvant hormone therapy use in older breast cancer survivors. Cancer 117: 398-405

This work is published under the standard license to publish agreement. After 12 months the work will become freely available and the license terms will switch to a Creative Commons Attribution-NonCommercial-Share Alike 3.0 Unported License. 